\title{
L1 Cognitive Skills Transfer in the Process of Learning L2 of Dependent Scripts
}

\author{
Utami Dewi ${ }^{1}$ Berlin Sibarani ${ }^{2}$ Sumarsih $^{3}$ \\ ${ }^{1}$ English Department, Universitas Islam Negeri Sumatera Utara ${ }^{123}$ English Applied Linguistic Program, \\ Postgraduate School, Universitas Negeri Medan
}

\begin{tabular}{|c|c|}
\hline ARTICLE INFO & ABSTRACT \\
\hline $\begin{array}{l}\text { Article history: } \\
\text { Received Jan 13, } 2020 \\
\text { Revised April 02, } 2020 \\
\text { Accepted Jun 26, } 2020\end{array}$ & $\begin{array}{l}\text { Language transfer is one of the important areas in second language } \\
\text { acquisition research. This study aims to describe the process of } \\
\text { transfer L1, Bahasa Indonesia, cognitive skills to L2, English, } \\
\text { cognitive skills of dependent scripts. Cognitive skills are the skills } \\
\text { that support decoding, such as rapid automatized naming (RAN) and }\end{array}$ \\
\hline $\begin{array}{l}\text { Keywords: } \\
\text { L1 } \\
\text { L2 } \\
\text { Cognitive skills } \\
\text { Dependent Scripts }\end{array}$ & $\begin{array}{l}\text { working memory (WM). This research was conducted with } \\
\text { descriptive qualitative research design, with case study. The subjects } \\
\text { of the study were } 15 \text { students who speak Bahasa as the first language } \\
\text { (L1) and learn English as the second language (L2). Bahasa and } \\
\text { English are the language which have the same scripts, dependent } \\
\text { scripts. The subjects were given the rapid automatized naming } \\
\text { (RAN) test and working memory (WM) test. The data of this study }\end{array}$ \\
\hline $\begin{array}{l}\text { Clonflict of Interest: } \\
\text { None }\end{array}$ & $\begin{array}{l}\text { was analyzed with two data analysis techniques, they were non- } \\
\text { parametric statistics and qualitative data analysis. The finding of this }\end{array}$ \\
\hline $\begin{array}{l}\text { Funding: } \\
\text { None }\end{array}$ & $\begin{array}{l}\text { transfer RAN and WM as the subskills, that most of the students } \\
\text { made different errors both in L1 and L2 RAN and WM, and they } \\
\text { have different levels of achievement in L1 and L } 2 \text { cognitive skills. }\end{array}$ \\
\hline
\end{tabular}

Corresponding Author: Utami Dewi, English Applied Linguistic, Postgraduate School, State University of Medan. E-mail: utamimecca@gmail.com

Copyright@Association of Language Teachers in Southeast Asia. All rights reserved

\section{Introducation}

1.1 Introduce the Problem

Bilingualism is an important issue in applied linguistic research. Bilingualism can be found in every society and in different age rages and stages of life. In Indonesia, it is now common that young learners start learning English as a foreign or second language at the very beginning of their formal education. Nowdays, many schools are bilingual programs. Bilingual students, sometimes, has different level of proficiency in macro skills such as reading, writing, speaking and listening. In bilingual studenrs, they speak first language (L1) and also able to speak second language or foreign language (L2). The L1 proficiency influences the L2 proficiency.

Many research has been focussed on reading in bilingualism. Reading skills in the first language affect to the reading skills in second languge. Many factors also influence development of reading, such as: cognitive and linguistics skills. Cognitive skills are described by analyzing rapid automatized naming, and short term memory. L1 rapid naming automatized (RAN), and working memory (WM), phonological shortterm memory are cognitive skills which also transfer to L2 outcomes. As some of research showed that children's reading comprehension has been shown to be influenced by their verbal working memory, their rapid, authomatic decoding of words (word recognition); their phonological skills (Shankweiler, 1989); their lexical quality with well specified and abundant representation of orthography, phonology and flexible 
representation of meaning (Perfetti, 2007). Many studies discussed about cross-language transfer of skills from L1 to L2 which alphabetical languages and English (Kahn-Horwitz and colleagues ,2005; Abu- Rabia \& Siegel, 2002, Deacon, Commissaire, Chen, \& Pasquarella, Abu-Rabia and Sanitsky (2010), but it is limited research about L1, Bahasa, skills transfer to L2, English, skills. Therefore, it is challenge to examine the process of skills from Bahasa as first language (L1) which transferred in the process of learning English as second language (L2).

Lado (1954) states the crux of contrastive analysis which relies on similarities and differences in language structure between a first and second language that are expected to explain positive and negative transfer between L1 and L2 skills. The skills developed in the context of one's first language influence the development of L2 skills. Certain types of errors in the L2 may reflect structures in the L2 that differ considerably from those in the L1 which called as negative transfer. When the L1 and L2 are similar, fewer errors will be made in light of these common features, and learners may thus be able to rely on structures from the L1 when acquiring the L2 which called as positive transfer. Sometimes, the negative transfer is not always about the errors in L2, but it delays the development of the learning process in L2, and the positive transfer also means that L1 facilitates the development of learning L2. Futhermore, some contversial hypotheses about cross-language transfer are discussed in many researches to answer the process of language transfer, such as: language interdependence hyphothesis (LIH), linguistic threshold hyphothesis (LTH), central processing hyphothesis $(\mathrm{CPH})$, and scripts dependent hyphothesis (SDH). Those hypotheses discussed how the L1 skills transfer in the process of learning L2 with different hypothesis among them.

Based on the hyphothesis, this study discussed the transfer of L1, Bahasa, cognitive skills into L2, English, cognitive skills in which Bahasa Indonesia and English have the same writing sytems which called as dependent scripts. Specifically, the cognitive skills which discussed are rapid naming automatized (RAN), and working memory (WM). Investigating the process of L1 cognitive skills transfer in the process of learning L2 dependent script and the reason underlying the transfer are done in this study. Indonesian-English bilingual program which has script dependent was examined in cognitive skills.

\section{Literature Review}

\subsection{Cross Language Transfer}

During the heyday of contrastive analysis (CA) the influence of the first language was thought to have a negative effect in the $\mathrm{L} 2$, therefore the term insterference was used to refer to this phenomenon. This term is often used in Weinreich (1953). This was closely related to behaviorism, as established by Skinner (1957). During the 1950's and 60's the term transfer was used, which originated in psychology where it indicated any previous knowledge being applied to new knowledge. Odlin (1989) stated, "transfer is the influence resulting from similarities and differences between the target language and any other language that has been previously acquired".

Then, cross language transfer theories discuss about how the L1 skills transfer to L2 skills. Linguistic interdependence hypothesis (LIH; Cummins, 1979, 1980, 1981), which assumes that two languages can be transfer automatically from L1 to L2. It means that if a learner has a good level of L1, a similar level of skills is possible in L2, in other words, L1 supports the development of L2. While, if a learner has low skills in L1, so the learner also has the low skills in L2. Other researcher that support the LIH, Yamashita (2002) compared English as a foreign language (EFL) reader with different reading proficiency levels in their L1 Japanese and L2 English and found that L2 readers with a higher L1 reading ability were able to achieve better L2 reading proficiency. It means that poor L1 skills led to poor L2 abilities.

In addition to LIH, the linguistic threshold hypothesis (LTH) argued that the level of conquest of L2 is related to the level of conquest of the first language and that if one language is inadequate, the deficits will appear in the other (Cummins, 1979). He suggested that the aspects of bilingualism which otherwise exert positive influence on a child's cognitive growth are not likely to come into effect before he has reached a certain minimum of linguistic competence in the L2. Based on the work of Clarke and Cziko (1980), the linguistic threshold hypothesis is also referred to as the short-circuit hypothesis. More recently, this hypothesis is more commonly referred to as the LTH (Bernhardt and Kamil 1995). Linguistic threshold hypothesis assumes the L1 skills facilitates the development of L2 with the requirement of minimal ability of L2.

The next hyphothesis is central processing hyphothesis $(\mathrm{CPH})$. $\mathrm{CPH}$ theorizes that there are cognitive and linguistic processes which transfer across languages and which facilitates reading acquisition in any language. The theory emphasizes the role of cognitive and linguistic processes in the development of reading in an L1 or L2 (Geva, 2006: 1) ignoring the differences in orthographic structure that exist in languages. The $\mathrm{CPH}$ posits that individuals with deficient cognitive and linguistic skills will experience difficulty in acquiring basic reading skills, regardless of the language and script involved, and regardless of whether it is their L1 or L2 (Aquino, 2012: 3). According to the central processing hypothesis (Geva \& Siegel, 2000), the acquisition of reading skills in a foreign language is dependent on the role of the basic 
cognitive skills, such as short-term memory and on the language skills, such as phonological (Durgunoglu, Nagy, \& Hancin-Bhatt, 1993). Central processing hyphothesis posits that cognitive and linguistic skills in the first language contribute or contruct the skills in the second language. It assumes that in inadequate cognitive and linguistic skills will face difficulties in acquiring the second language (Geva \& Siegel, 2000)

However, there are also researches, such as Abu-Rabia, (2001) and Abu-Rabia \& Siegel, (2003), which support the script-dependent hypothesis (SDH), and state that when the spelling of the two languages differ in depth, the transfer of spelling knowledge cannot be transferred. There are also studies that showed that the degree of syntactic awareness in L1 was not transferred to L2 (Chiappe, Siegel \& Wade-Woolley, 2002). SDH assumes that if the two language have the similarities, the posive transfer happens, but if the two languges have different in depth of writing system ans structures, the negative transfer happens.

2.2. Cognitive Skills

Cognitive skills are the mental process enabling one person to proceed information. Cognitive skills that support decoding, such as: attention, rapid naming, visual discrimination, visual sequential processing, immediate memory and working memory must be automatic for succesful reading. In this study, rapid automatized naming and working memory are examined as the cognitive skills. Firstly, Naming speed is an underlying component of cognition that refers to the ability to name serially presented simple stimuli as fast as possible. Rapid automatized naming tests involve presenting the pictures of objects and asking the students to name the items as quickly as possible. RAN has been found to relate directly to word reading ability, after controlling for PA and other underlying cognitive abilities (i.e., nonverbal reasoning) (Wolf \& Bowers, 1999).

Another cognitive skill that discussed in this research is working memory (WM). The term working memory refers to a dynamic brain system that enables human beings to store and manipulate information while engaging in complex cognitive task such as comprehension, problem solving, etc. (Baddley and Hitch, 1974; Savage, Lavers, and Pillay, 2007). Futhermore, working memory (WM) refers to processing resources of limited capacity that individuals need to maintain information while simultaneously acting on the same or other information. In this study, the students were asking to listen the sentence, then answer the true or false of the sentence, and write the last word in the sentence. In this case, the working memory examined the cognitive skills in recall the short-term memory and long-term memory.

\section{Method}

This research was conducted with descriptive qualitative research design, with. The subjects of this study are 15 Indonesian students who learn English. These data were collected by using tests: rapid automatized naming test and working memory test. The data of this study was analyzed with two data analysis techniques. The first is non-parametric statistics: Spearman's correlation and Mann Withney U test. The second is qualitative data analysis proposed by Miles, Huberman and Saldana (2014:14).

\section{Results and Discussion}

To find out the transfer of L1 cognitive skills into the process of learning L2 of dependent scripts was by correlating the score of the L1 cognitive skills and L2 cognitive skills of dependent scripts with Spearman's correlation on the assumption that the scores of two tests reflected the skills mastered in the two languages and significant correlation means that there is significant transfer from L1 cognitive skills to L2 cognitive skills of dependent scripts . The result of the data analysis was represented by the result of hypothesis testing. If Ho is accepted means there is no significant correlation between the L1 and L2 cognitive skills of dependent scripts, therefore, it is interpreted that the transfer of L1 cognitive skills to L2 cognitive skills of dependent scripts does not happen. On the other hand, if Ha is accepted means there is significant correlation between L1 and L2 cognitive skills of dependent scripts. Therefore, it shows that the transfer happens from L1 cognitive skills to L2 cognitive skills of dependent scripts.

The correlational analyses were conducted by calculating the ranks of the scores of two tests from the one group ( $\mathrm{N}=15)$, and were also calculated scores to examine the relation between students' cognitive skills in L1 and L2 of dependent scripts. The data of students' L1 and L2 scores of cognitive skills and the the ranks of the students' score are described in table 1. There are six students who got the highest score (60) in L1 cognitive skills and two students who got the highest score (58) in L2 cognitive skills. In this analysis, the rank of the students' score both in L1 and L1 was used to calculate the correlation. 
Table 1. The Ranking of Students' Cognitive Skills of Dependent Scripts

\begin{tabular}{cccccc}
\hline NO & $\begin{array}{c}\text { INITIAL } \\
\text { NAME }\end{array}$ & $\begin{array}{c}\text { L1 (Bahasa) } \\
\text { Cognitive } \\
\text { Skills }\end{array}$ & Rank & $\begin{array}{c}\text { L2 (English) } \\
\text { Cognitive Skills }\end{array}$ & Rank \\
\hline 1 & MR & 59 & 9.5 & 51 & 14 \\
2 & MZM & 60 & 3.5 & 58 & 1.5 \\
3 & WR & 59 & 9.5 & 54 & 10.5 \\
4 & HA & 60 & 3.5 & 50 & 15 \\
5 & EPI & 58 & 14 & 57 & 4 \\
6 & ZHD & 59 & 9.5 & 58 & 1.5 \\
7 & AN & 59 & 9.5 & 56 & 7 \\
8 & FA & 58 & 14 & 56 & 4 \\
9 & DLH & 60 & 3.5 & 57 & 12.5 \\
10 & RIW & 60 & 3.5 & 53 & 12.5 \\
11 & AF & 58 & 14 & 54 & 7 \\
12 & WP & 59 & 9.5 & 53 & 9 \\
13 & RW & 59 & 9.5 & 56 & 4 \\
14 & RAP & 60 & 3.5 & 55 & 57 \\
15 & NH & 60 & 3.5 & & 7 \\
\hline
\end{tabular}

Table 2. Correlations of L1 and L2 Cognitive Skills of Dependent Scripts

\begin{tabular}{lllrr}
\hline & & L1 cognitive skills & L2 cognitive skills \\
\hline Spearman's rho & L1 cognitive & Correlation & 1.000 & .003 \\
& skills & Coefficient & & .992 \\
& & Sig. (2-tailed) & 15 & 15 \\
& N & Correlation & .003 & 1.000 \\
& skills & Coefficient & .992 & 15 \\
& & Sig. (2-tailed) & 15 &. \\
& & $\mathrm{~N}$ & & \\
& & &
\end{tabular}

Table 2 presents the correlations between L1, Bahasa, cognitive skills and L2, English, cognitive skills of dependent scripts. The table 2 presents Spearman's correlation, its significance value and the sample size that the calculation was based on the rank. In this example, we can see that Spearman's correlation coefficient, $r_{s}$, is 0.003 , and that this is statistically significant $(p=0.992)$. The $r_{s}$, is 0.003 means the correlation is very weak. The significance rank Spearman 0.992 is higher than $0.05(0.992>0.05)$ means that the Ho is accepted. Therefore, there is no significant correlation between L1 and L2 cognitive of dependent scripts. It means that L1 cognitive skills was not significantly transferred in the process of learning L2 of dependent scripts.

The next, the Mann- Whitney U test was used on the assumption that both of L1 and L2 cognitive skills are not significantly different which means that Ho is accepted. If L1 cognitive skills are significantly higher than L2 cognitive skills of dependent scripts which means that Ha is accepted.

Table 3. Ranks

\begin{tabular}{llccc}
\hline & Groups & N & Mean Rank & Sum of Ranks \\
\hline Cognitive Skills & 1 & 15 & 22.80 & 342.00 \\
& 2 & 15 & 8.20 & 123.00 \\
& Total & 30 & & \\
\hline
\end{tabular}

The table above describe that the mean rank of L1 cognitive skills is 22.80 and the mean rank of L2 is 8.20 . If the p-value is below the usually agreed alpha risk of 5 percent $(0.05)$, the null hypothesis can be rejected and at least one significant difference can be assumed. 
Table 4 Test Statistics ${ }^{\mathrm{a}}$

\begin{tabular}{lr}
\hline & Cognitive Skills \\
\hline Mann-Whitney U & 3.000 \\
Wilcoxon W & 123.000 \\
Z & -4.593 \\
Asymp. Sig. (2-tailed) & .000 \\
Exact Sig. [2*(1-tailed Sig.)] & $.000^{\mathrm{b}}$ \\
\hline
\end{tabular}

a. Grouping Variable: Groups

b. Not corrected for ties.

From this data, it can be concluded that L1 cognitive skills was statistically significantly higher than L2 cognitive skills $(U=3.000, p=.000)$ and the result of sig or $p$-value $0.000<0.05$. Thus, the result of hypothesis testing is that null hypothesis is rejected and the alternative hypothesis is accepted, therefore, L1 cognitive skills are significantly higher than L2 cognitive skills of dependent scripts. From this finding, it can be concluded that L1 cogntive skills were not transferred to L2 cognitive skills because the score of L1 and L2 cognitive skills were significant different.

The first finding of hypothesis testing was that there was no significant correlation between L1 and L2 cognitive skills of dependent scripts. The secondly, L1 cognitive skills were significantly higher than L2 cognitive skills. From the two findings, it can be concluded that L1 cognitive skills were not significantly transferred to L2 cognitive skills of dependent scripts. In accordance of Spearman's correlation and MannWhitney U test findings, the following description are the process of transfer from L1 cognitive skills to L2 cognitive skills of dependent scripts which discussed detail in the process of transfer L1 RAN and WM to L2 RAN and WM of dependent scripts. It has been explained that in this research the cognitive skills consist of rapid naming automatized (RAN) and working memory (WM).

Firstly, RAN means that students are able to recall the long-term memory about the object and naming the object rapidly. In this study, RAN was used to examined the students to name of the pictures that showed rapidly in L1 and L2. The students were showed the 20 pictures, then the students named the pictures in L1: 1. buku, 2. pensil, 3. kursi, 4. penghapus, 5. kotak, 6. papan tulis, 7. gelas, 8. topi, 9. sendok, 10. lemari buku, 11. mata, 12. sepatu, 13. piring, 14. sekolah, 15. pintu, 16. hidung, 17. guru, 18. jam dinding, 19. murid, 20. sandal. Then, the students were showed the same pictures again and the students named in L2: 1. book, 2. pencil, 3. chair, 4. eraser, 5. box, 6. white board, 7. glass, 8. hat, 9. spoon, 10. bookcase, 11. eye, 12. shoe, 13. plate, 14. school, 15. door, 16. nose, 17. teacher, 18. clock, 19. student, 20. slippers.

L2 RAN.

After analyzing the data in L1 and L2, the following table describes the transfer from L1 RAN to

Table. 5. The Transfer of L1 RAN to L2 RAN of Dependent Scripts

\begin{tabular}{|c|c|c|c|c|c|}
\hline No & $\begin{array}{l}\text { INITIAL } \\
\text { NAME }\end{array}$ & No. of Transfer & $\begin{array}{l}\text { No. of } \\
\text { L1 } \\
\text { Error }\end{array}$ & $\begin{array}{l}\text { No. of } \\
\text { L2 } \\
\text { Error }\end{array}$ & Coding \\
\hline 1 & MR & $\begin{array}{c}1,2,3,4,5,7,8,9,11 \\
12,13,14,15,16,17,18,20\end{array}$ & 14 & $\begin{array}{c}6,10,14 \\
19\end{array}$ & $\begin{array}{c}\text { [T-RAN-TF15 } \\
(1,2,3,4,5,7,8,9,11,12,13,14,15 \\
, 16,17,18,20)-M R]\end{array}$ \\
\hline 2 & MZM & $\begin{array}{c}1,2,3,4,5,6,7,8,9,10,11 \\
12,13,14,15,16,17,18,19, \\
20\end{array}$ & - & - & [T-RAN-TF20-MZM] \\
\hline 3 & WR & $\begin{array}{c}1,2,3,4,5,6,7,9,11 \\
12,13,14,15,16,17,18,19\end{array}$ & - & $8,10,20$ & $\begin{array}{c}\text { [T-RAN-TF17 } \\
(1,2,3,4,5,6,7,9,11,12,13,14,15 \\
, 16,17,18,19)-\mathrm{WR}]\end{array}$ \\
\hline 4 & HA & $\begin{array}{c}1,2,3,4,5,6,7,9,11 \\
12,13,14,15,16,17,18,19\end{array}$ & - & $8,10,20$ & $\begin{array}{c}{[\mathrm{T}-\mathrm{RAN}-} \\
\mathrm{TF} 17(1,2,3,4,5,6,7,9,11 \\
12,13,14,15,16,17,18,19)- \\
\text { HA] }\end{array}$ \\
\hline 5 & EPI & $\begin{array}{c}1,2,3,4,5,6,7,8,9,10,11 \\
12,13,14,15,16,17,18,19 \\
20\end{array}$ & - & - & [T-RAN-TF20-EPI] \\
\hline 6 & ZHD & $\begin{array}{c}1,2,3,4,6,7,8,9,10 \\
11,13,14,15,16,17,18,19\end{array}$ & 5 & 20 & $\begin{array}{c}\text { [T-RAN-TF18 } \\
(1,2,3,4,6,7,8,9,10,11,13,14,15 \\
16,17,18,19)-\mathrm{ZHD}]\end{array}$ \\
\hline
\end{tabular}

SALTeL Vol. 3, No. 2, 2020: 8- 16 


\begin{tabular}{|c|c|c|c|c|c|}
\hline 7 & $\mathrm{AN}$ & $\begin{array}{c}1,3,4,6,7,8,10,11, \\
12,13,14,15,16,17,19,\end{array}$ & 5 & $\begin{array}{c}2,9,18 \\
20\end{array}$ & $\begin{array}{c}{[\mathrm{T}-\mathrm{RAN}-} \\
\mathrm{TF} 15(1,3,4,6,7,8,10,11, \\
12,13,14,15,16,17,19)-\mathrm{AN}]\end{array}$ \\
\hline 8 & FA & $\begin{array}{c}1,2,3,4,6,7,8,10,11 \\
12,13,15,16,17,19\end{array}$ & 5,14 & $9,18,20$ & $\begin{array}{c}\text { [T-RAN-TF15 } \\
(1,2,3,4,6,7,8,10,11,12,13,15,1 \\
6,17,19)-\mathrm{FA}]\end{array}$ \\
\hline 9 & DLH & $\begin{array}{c}1,2,3,4,5,6,7,8,9,10 \\
11,12,13,14,15,16 \\
17,18,19\end{array}$ & - & 20 & $\begin{array}{c}{[\text { T-RAN-TF19 }} \\
(1,2,3,4,5,6,7,8,9,10,11,12,13 \\
14,15,16,17,18,19)- \text { DLH] }\end{array}$ \\
\hline 10 & RIW & $\begin{array}{c}1,2,3,4,5,6,7,8,10 \\
11,12,13,14,15,16 \\
17,19,20\end{array}$ & - & 9,18 & $\begin{array}{c}{[\text { T-RAN-TF18 }} \\
(1,2,3,4,5,6,7,8,10,11,12,13,14 \\
, 15,16,17,19,20) \text {-RIW] }\end{array}$ \\
\hline 11 & $\mathrm{AF}$ & $\begin{array}{c}1,2,3,4,5,6,7,9,11, \\
12,13,15,16,17,18,19,20\end{array}$ & 14 & 8,10 & $\begin{array}{c}{[\mathrm{T}-\mathrm{RAN}-} \\
\mathrm{TF} 17(1,2,3,4,5,6,7,9,11,12,13, \\
15,16,17,18,19,20)-\mathrm{AF}]\end{array}$ \\
\hline 12 & WP & $\begin{array}{c}1,2,3,4,5,6,7,10,11,12,13 \\
, 14,15,16,17,19,20\end{array}$ & - & $8,9,18$ & $\begin{array}{c}\text { [T-RAN- } \\
\text { TF17(1,2,3,4,5,6,7,10,11,12,1 } \\
3,14,15,16,17,19,20)-\mathrm{WP}]\end{array}$ \\
\hline 13 & RW & $\begin{array}{c}1,2,3,4,5,6,7,8,9,10,11,1 \\
2,13,14,16,17 \\
18,19 \\
20\end{array}$ & 15 & - & $\begin{array}{c}{[\text { T-RAN-TF19 }} \\
(1,2,3,4,5,6,7,8,9,10,11,12,13 \\
14,16,17,18,19,20)-\mathrm{RW}]\end{array}$ \\
\hline 14 & RAP & $\begin{array}{c}1,2,3,4,5,6,7,8,9,10,11,1 \\
2,13,14,15,16 \\
17,19,20\end{array}$ & - & 18 & $\begin{array}{c}{[\text { T-RAN-TF19 }} \\
(1,2,3,4,5,6,7,8,9,10,11,12,13 \\
14,15,16,17,19,20)- \text { RAP }]\end{array}$ \\
\hline 15 & $\mathrm{NH}$ & $\begin{array}{c}1,2,3,4,5,6,7,8,10,11 \\
12,13,14,15,16,17 \\
18,19,20 \\
\end{array}$ & - & 9 & $\begin{array}{c}\text { [T-RAN-TF19 } \\
(1,2,3,4,5,6,7,8,10,11,12,13,14 \\
, 15,16,17,18,19,20)-\mathrm{NH}]\end{array}$ \\
\hline
\end{tabular}

The data showed that only two of the students transferred the RAN from L1 to L2. The process of transfer means the students were able to answer the names of the pictures in L1 and L2 RAN correctly. For example, two of students transferred the L1 to L2 RAN.

Data1: [T-RAN-TF20-MZM]

Data 2: [T-RAN-TF20-EPI]

From data 1 and 2, MZM and EPI named the pictures in Bahasa Indonesia: buku, pensil, kursi, penghapus, kotak, papan tulis, gelas, topi, sendok, lemari buku, mata, sepatu, piring, sekolah, pintu, hidung, guru, jam dinding, murid, sandal, and in English: book, pencil, chair, eraser, box, white board, glass, hat, spoon, bookcase, eye, shoe, plate, school, door, nose, teacher, clock, student, slippers. The data above described that two of the students named the 20 pictures in L1 and L2 rapidly and correctly. MZM was finished naming the pictures in L1 with the time 0:16:16 and in L2 with the time 0:19:43. EPI named the all pictures in L1 with the time 0:32:80 and in L2 0:23:16.

The following data showed that four students transferred 19 words from L1 to L2.

Data 3: [T-RAN-TF19 $(1,2,3,4,5,6,7,8,9,10,11,12,13,14,15,16,17,18,19)-D L H]$ Not transferred No.20 of L2: sendal

Data 4: [T-RAN-TF19 $(1,2,3,4,5,6,7,8,9,10,11,12,13,14,16,17,18,19,20)-R W]$ Not transfer No. 15 of L1: kardus

Data 5: [T-RAN-TF19 $(1,2,3,4,5,6,7,8,9,10,11,12,13,14,15,16,17,19,20)-R A P] ~ N o t$ transferred No. 18 of L2: o'clock

Data 6: [T-RAN-TF19 $(1,2,3,4,5,6,7,8,10,11,12,13,14,15,16,17,18,19,20)-N H]$ Not transferred No. 9 of L2: whitedrop

From data 3,4,5,6, each of students told mistake of a name of the picture in L1 or L2. Three of the students made the mistake in L2. DLH named sendal for slippers, RAP named o'clock for clock, NH named whiterop for bookcase. While, RIW made the mistake in naming the word in L1 kardus for kotak. It meant that DLH did not transfer the word sendal (L1) to slipper (L2), RAP did not transfer the word jam dinding (L1) to clock (L2), NH did not transfer the word lemari buku (L1) to bookcase (L2), while RIW did not transfer the word kotak (L1) to box (box). Others transferred 18,17, and 15 word from L1 to L2.

From the table above, it showed that some of the students made errors in naming the object in L1, but they did not make the same error in L2 which meant that the error of L1 RAN was not transferred to L2 
RAN errors because they made error in different objects. For example, MR made error in number 14 of L1 RAN but she did not make the same errors in L2, she made errors in number 6, 10, 14, and 19 of L2 RAN. Other students who made different errors in L1 and L2 RAN were ZHD, AN, FA, AF, and RW. These data described that the transfer from L1 RAN to L2 RAN did not significantly occurred in the process of learning L2 of dependent scripts.

Secondly, working memory (WM) was also tested to find out the transfer of L1 to L2 cognitive skills. In working memory, the students were listened 20 sentences (see in Appendix), then students answer true or false of 20 sentences and write the last word of the sentences. Here is the example of WM question in L1 and L2.

Data 7: [T-WM- Bahasa-No.7] Wortel adalah binatang.

Data 8: [T-WM-English-No.7] A carrot is animal.

From data 7 and 8, it can be seen that students had listened the sentences which had same meaning in L1 and L2. In Bahasa, wortel adalah binatang, but in English, A carrot is an animal which have the same meaning.

The analysis based on the students' errors which made in L1 and L2, the transfer occurred if the students answered correctly the same number both in L1 and L2 WM or made errors in the same number in L1 and L2 WM, so the L1 WM was not significantly higher than L2 WM or vice versa.

Table 6. The Transfer of L1 WM to L2 WM of Dependent Scripts

\begin{tabular}{|c|c|c|c|c|c|}
\hline No & $\begin{array}{c}\text { INITIAL } \\
\text { NAME }\end{array}$ & $\begin{array}{l}\text { No. of } \\
\text { L1 } \\
\text { Error }\end{array}$ & No. of L2 Error & Transfer & Coding \\
\hline 1 & MR & - & $\begin{array}{l}8 \mathrm{C}, 1 \mathrm{D}, 2 \mathrm{D}(\mathrm{sec} \mathrm{I}) \\
10 \mathrm{C}, 10 \mathrm{D}(\mathrm{sec} \mathrm{II})\end{array}$ & 35 & [T-WM-DS-TF35-MR] \\
\hline 2 & MZM & - & $10 \mathrm{C}, 10 \mathrm{D}$ & 38 & $\begin{array}{l}\text { [T-WM-DS-TF38- } \\
\text { MZM] }\end{array}$ \\
\hline 3 & WR & $\begin{array}{l}5 \mathrm{C} \quad(\mathrm{Sec} \\
\mathrm{II})\end{array}$ & $\begin{array}{l}\text { 2D (Sec I) } \\
\text { 3D, 10D (Sec II) }\end{array}$ & 36 & [T-WM-DS-TF36-WR] \\
\hline 4 & HA & - & $\begin{array}{l}1 \mathrm{C}, 2 \mathrm{C}, 8 \mathrm{C}, 2 \mathrm{D} \quad(\mathrm{Sec} \\
\mathrm{I}) \\
10 \mathrm{C}, 10 \mathrm{D}(\mathrm{Sec} \mathrm{II})\end{array}$ & 34 & [T-WM-DS-TF34-HA] \\
\hline 5 & EPI & $\begin{array}{r}1 \mathrm{C}, 5 \mathrm{C} \\
(\mathrm{Sec} I)\end{array}$ & $\begin{array}{l}1 \mathrm{C}, 1 \mathrm{D}(\mathrm{Sec} \mathrm{I}) \\
8 \mathrm{C}(\mathrm{Sec} \mathrm{II})\end{array}$ & 35 & [T-WM-DS-TF35- EPI] \\
\hline 6 & ZHD & - & $\begin{array}{l}\text { 9D, 10D }(\sec I) \\
7 \mathrm{D}(\operatorname{Sec} \mathrm{II})\end{array}$ & 37 & [T-WM-DS-TR37-ZHD] \\
\hline 7 & AN & - & - & 40 & [T-WM-DS-TR40-AN] \\
\hline 8 & FA & - & $2 \mathrm{C}(\mathrm{Sec} \mathrm{II})$ & 39 & [T-WM-DS-TR39-FA] \\
\hline 9 & DLH & - & 2D, 10D (Sec II) & 38 & [T-WM-DS-TR38-DLH] \\
\hline 10 & RIW & - & $\begin{array}{l}2 \mathrm{D}(\operatorname{Sec} \mathrm{I}) \\
7 \mathrm{C}, 8 \mathrm{C}, 2 \mathrm{D}, \quad 10 \mathrm{D} \\
(\operatorname{Sec} \mathrm{II})\end{array}$ & 36 & [T-WM-DS-TR36-RIW] \\
\hline 11 & $\mathrm{AF}$ & $\begin{array}{l}5 \mathrm{C} \quad(\mathrm{Sec} \\
\mathrm{I})\end{array}$ & $\begin{array}{l}\text { 9D, 10D (Sec I) } \\
\text { 5C,4D (Sec II) }\end{array}$ & 35 & [T-WM-DS-TR35-AF] \\
\hline 12 & WP & $\begin{array}{l}1 \mathrm{C} \quad(\mathrm{Sec} \\
\mathrm{I})\end{array}$ & $\begin{array}{l}1 \mathrm{C}, 2 \mathrm{C}(\mathrm{Sec} \mathrm{I}) \\
3 \mathrm{C}, 10 \mathrm{C}(\mathrm{Sec} \mathrm{II})\end{array}$ & 35 & [T-WM-DS-TR35-WP] \\
\hline 13 & RW & $\begin{array}{l}2 \mathrm{C} \quad(\mathrm{Sec} \\
\mathrm{I})\end{array}$ & $\begin{array}{l}2 \mathrm{C}, 3 \mathrm{C}, 2 \mathrm{D}, 9 \mathrm{D} \quad(\mathrm{Sec} \\
\mathrm{I})\end{array}$ & 35 & [T-WM-DS-TR35-RW] \\
\hline 14 & RAP & - & $\begin{array}{l}8 \mathrm{C}, 8 \mathrm{D}(\mathrm{Sec} \mathrm{I}) \\
8 \mathrm{C}, 10 \mathrm{D}(\mathrm{Sec} \mathrm{II})\end{array}$ & 36 & [T-WM-DS-TF36-RAP] \\
\hline 15 & $\mathrm{NH}$ & - & $10 \mathrm{C}, 8 \mathrm{D}(\mathrm{Sec} \mathrm{I})$ & 38 & [T-WM-DS-TF38-NH] \\
\hline
\end{tabular}

From data above, only one of the students transferred all the working memory from L1 to L2. Data: [T-WM-DS-TR40-AN]

AN answered correctly the true false and wrote the last words of 20 in L1 and L2 WM.

Then, most of the students answered correctly all the numbers in L1, but they made some errors in L2. From the table above, it showed that MR answered all numbers correctly in L1, but MR made 5 errors in L2 no. 8C,1, 2D in section I and 10C, 10D in section II. It meant that MR transferred the 35 numbers. MZM answered all number correctly, but made errors in L2 no. 10C and 10D. It meant MZM transferred 38 numbers. HA answered all numbers correctly in L1, but made errors in L2 no. 1C, 2C, 8C, 2D in section I, 
and no. 10C, 10D (sec II). It meant HA transferred 34 numbers. ZHD answered all the numbers correctly in L1, but made errors in 9D, 10D in section I, and 7D in section II. It meant that ZHD transferred 37 numbers. From the description, the range of the true and false of L1 and L2 was significant different, therefore, the process of L1 WM transfer to L2 WM was not significant.

The data also showed that five students made errors both in L1 and L2. The students made errors in L1, but the errors were not transferred to L2 skills. It can be seen that they had different errors in L1 and L2 WM. WR made an error in L1 WM no. 5C section II, and three errors in L2 WM no. 2D section I and 3D, $10 \mathrm{D}$ section II. It meant that WR transferred $36 \mathrm{WM}$ from L1 to L2, but the error in L1 WM was not transferred to L2 WM. EPI made two errors in L1 WM no. 1C, 5C section I and three errors in L2 WM no. 9D, 10D section I and no 7D section II. It means that EPI transferred $37 \mathrm{WM}$ from L1 to L2. AF made an error in L1 no. 5C section I, and four errors in L2 no. 9D, 10D section I, and 5C, 10D section II. It means AF transferred $35 \mathrm{WM}$ from L1 to L2. WP made an error in L1 WM no. 1C section I, and four errors in L2 WM no. $1 \mathrm{C}, 2 \mathrm{C}$ section I, and $1 \mathrm{C}, 2 \mathrm{C}$ section II. It meant that WP transferred $35 \mathrm{WM}$ from L1 to L2. RW made an error in L1 no. 2C section I, and four errors in L2 no. 2C, 3C, 2D, 9D section I. It meant that RW transferred $35 \mathrm{WM}$ from L1 to L2.

From the description above, it can be concluded that L1, Bahasa, working memory was not transferred to L2, English working memory because the students made different errors both in L1 and L2 working memory. Conversely, the errors which occurs in the first language were not transferred to the second language. Most of the students made many errors in L2, it means the development of L2 are lower than L1 working memory. The working memory deals with the students' ability in listening the language, and to recall the short-term memory and long-term memory, so in this study, the students had problem to recall the long-term memory and the short-term memory.

At last, the process of transfer happened if the L1 cognitive skills was same as L2 cognitive skills or if the students had the same errors both in L1 and L2 cognitive skills. Otherwise, the process of L1 cognitive skills was not transferred to L2 cognitive skills if the L1 cognitive skills was significantly higher or lower than L2 cognitive skills or if the students had different errors in L1 and L2 cognitive skills. From the description above, it can be concluded that the process of L1 cognitive skills were not transferred to L2 cognitive skills of dependent scripts, because the range of the score between L1 and L2 RAN and WM were very high, and their L1 errors were not transferred to L2 errors. This finding proved the previous analysis of Spearman's correlation and Mann-Whitney that the L1 cognitive skills were not significantly transferred in the process of learning L2 of dependent scripts though there were transfer from L1 to L2 cognitive skills, but the transfer was very weak and it was not significant and it also proved by Mann-Withney $U$ test which found that the L1 cognitive skills was significantly higher than L2 cognitive skills.

\section{Conclusion}

In conclusion, L1, Bahasa, cognitive skills were not significantly transferred to L2, English, cognitive skills of dependent scripts. This is shown by the Spearman's correlation coefficient, $r_{s}$, is 0.003 , and statistically significant $(p=0.992)$ which means that there is weak correlation and it is not significant because the L1, Bahasa, cognitive skills are significantly higher than L2, English, cognitive skills which analyzed by Mann-Whitney U test. This study also found that the two subskills of cognitive skills, rapid automatized naming and working memory, were not transferred from the first language to the second language because the students made different errors in L1 RAN and L2 RAN, different errors in L1 WM and L2 WM, and most of student are good in L1 WM, but made many errors in L2 WM which means the development of L2 are delayed.

\section{References}

Abu-Rabia, S. (2000). Effects of exposure to literary Arabic on reading comprehension in diglossic situation. Reading and Writing: An Interdisciplinary Journal, 14, 147-157.

Abu-Rabia, S., \& Siegel, L. S. (2002). Reading, Syntactic, Orthographic, and Working Memory Skills of Bilingual Arabic-English Speaking Canadian Children. Journal of Psycholinguistic Research, 31, 661678. http://dx.doi.org/10.1023/A:1021221206119

Abu-Rabia, S. (2007). The role of morphology and short vowelization in reading Arabic among normal and dyslexic readers in Grades 3, 6, 9, and 12. Journal of Psycholinguistic Research, 36, 89-106.

Abu-Rabia, S., \& Sanitsky, E. (2010). Advantages of Bilinguals over Monolinguals in Learning a Third Language. Journal of the National Association for Bilingual Education, 33, 173-199.

Abu-Rabia, S. (2012). The role of morphology and short vowelization in reading morphological complex words in Arabic: Evidence for the domination of the morpheme/root-based theory in Reading Arabic. Creative Education, 3, Bernhardt, E. B., \& Kamil, M. L. 1995. Interpreting Relationships between L1 
and L2 Reading: Consolidating the Linguistic Threshold and the Linguistic Interdependence Hypotheses. Applied Linguistics, 16, 15-34.

Bradley, L., \& Bryant, P. E. (1983). Categorizing sounds and learning to read: A causal connection. Nature, 301(5899), 419-421.

Bernhardt, E. B., \& Kamil, M. L. (1995). Interpreting Relationships between L1 and L2 Reading: Consolidating the Linguistic Threshold and the Linguistic Interdependence Hypotheses. Applied Linguistics, 16, 15-34.

Cummins, J. (1976). The Influence of Bilingualism on Cognitive Growth: A Synthesis of Research Findings and Explanatory Hypotheses. Working Papers on Bilingualism No. 9, 1-43.

Cummins, J. (1978). Bilingualism and the development of metalinguistic awareness. Journal of CrossCultural Psychology, 9, 131-149.

Cummins, J. (1981). The role of primary language development in promoting educational success for language minority students. In California State Department of Education (Ed.), Schooling and language minority students: A theoretical framework (pp. 3-49). Los Angeles, CA: National Dissemination and Assessment Center.

Cummins, J. (1993). Bilingualism and second language learning. Annual Review of Applied Linguistics, 13, 51-70.

Cummins, J. (1994). Semilingualism. In Encyclopedia of language and linguistics (2nd ed.). Oxford: Elsevier Science.

Crystal, D. (1997). English as a global language. Cambridge: cambridge University Press.

Durgunoglu, A. Y., Nagy, W. E., \&Hancin-Bhatt, B. J. (1993). Cross-Language Transfer of Phonological Awareness. Journal of Educational Psychology.

Geva, E., \& Siegel, L. (2000). Orthographic and cognitive factors in the concurrent development of basic reading skills in two languages. Reading and Writing: An Interdisciplinary Journal, 12, 1-30. doi:10.1023/A:1008017710115. A Study into the Results of an Intervention Program of Linguistic Skills in English (L2) and Its Effect on Hebrew (L1) among Poor Readers: An Examination of the Cognitive-Retroactive Transfer (CRT) Hypothesis.

Hernandez and Li. (2007). The Age of Acquisition: Its neural and Computational Mechanism. Psychological Bulletin Copyright 2007 by the American Psychological Association 2007, Vol. 133, No. 4, 638-650.

Kendeou, P., van den Broek, P., White, M. J., \& Lynch, J. S. (2009). Predicting Reading Comprehension in Early Elementary School: The Independent Contributions of Oral Language and Decoding Skills. DOI: $10.1037 / \mathrm{a} 0015956$.

Lado, R. (1957). Linguistics across Cultures Applied Linguistics and Language Teachers. University of Michigan Press, Ann Arbor.

Odlin, T. (1989). Language Transfer. Cambridge: Cambridge University Press.

Perfetti CA. (2003). The universal grammar of reading. Scientific Studies of Reading.

Perfetti, Charles. (2007). Scientific Studies of Reading, v11 n4 p357-383 Sep 2007.

Saiegh-Haddad, E., \& Geva, E. (2008). Morphological Awareness, Phonological Awareness, and Reading in English-Arabic Bilingual Children. Reading and Writing: An Interdisciplinary Journal, 21, 481-504.

Wolf, Maryanne; Bowers. (1999). Journal of Educational Psychology, Vol 91(3), Sep 1999, 415-438.

Yamashita, Junko. (2007). The Relationship of Reading Attitudes between L1 and L2: An Investigation of Adult EFL Learners in Japan TESOL Quarterly Vol. 41, No. 1 (Mar., 2007), pp. 81-105 . Published by: Teachers of English to Speakers of Other Languages, Inc. (TESOL). 